\title{
Asymmetry and Leverage with News Impact Curve Perspective in Australian Stock Returns' Volatility during COVID-19
}

\author{
Najam Iqbal (D), Muhammad Saqib Manzoor and Muhammad Ishaq Bhatti *(D) \\ La Trobe Business School, La Trobe University, Melbourne 3108, Australia; n.iqbal@latrobe.edu.au (N.I.); \\ m.manzoor@latrobe.edu.au (M.S.M.) \\ * Correspondence: i.bhatti@latrobe.edu.au; Tel.: +61-3-9479-2715
}

\section{check for} updates

Citation: Iqbal, Najam, Muhammad Saqib Manzoor, and Muhammad Ishaq Bhatti. 2021. Asymmetry and Leverage with News Impact Curve Perspective in Australian Stock Returns' Volatility during COVID-19. Journal of Risk and Financial Management 14: 314. https:// doi.org/10.3390/jrfm14070314

Academic Editors: Robert Brooks and Thanasis Stengos

Received: 28 May 2021

Accepted: 6 July 2021

Published: 8 July 2021

Publisher's Note: MDPI stays neutral with regard to jurisdictional claims in published maps and institutional affiliations.

Copyright: (c) 2021 by the authors. Licensee MDPI, Basel, Switzerland. This article is an open access article distributed under the terms and conditions of the Creative Commons Attribution (CC BY) license (https:// creativecommons.org/licenses/by/ $4.0 /)$.

\begin{abstract}
This paper studies the effect of COVID-19 on the volatility of Australian stock returns and the effect of negative and positive news (shocks) by investigating the asymmetric nature of the shocks and leverage impact on volatility. We employ a generalised autoregressive conditional heteroskedasticity $(\mathrm{GARCH})$ model and extend the analysis using the exponential GARCH (EGARCH) model to capture asymmetry and allegedly leverage. We proxy the news related to the negative effect of COVID-19 on the Australian health system and its economy as bad news, and on the other hand, measures taken by government economic stimulus packages through their monetary and fiscal policies as good news. The S\&P ASX200 (ASX-200) index is used as a proxy to the Australian stock market, and we use value-weighted returns of the stocks listed on ASX-200 for the period 27 January 2020 to 29 December 2020. The empirical results suggest the EGARCH model fits better in capturing asymmetry and leverage than the GARCH model in estimating the volatility of the Australian stock returns. However, another interesting finding is that the EGARCH model with volatility equation without news demonstrates a larger (smaller) leverage effect of the negative (positive) shocks on the conditional volatility compared to its variant with the news.
\end{abstract}

Keywords: Australian stock market; volatility; COVID-19; GARCH; EGARCH; news impact curve

\section{Introduction}

The outbreak of COVID-19 in December 2019 and the consequent increase in uncertainty has had a massive financial effect on the real economy (Bakas and Triantafyllou 2020). The hike in uncertainty due to COVID-19 is typically associated with falling aggregate demand and, as a result, disrupting economic activity. The World Industrial Production Index fell by $4.5 \%$ in the first quarter of 2020 (Baumeister and Hamilton 2019). The IMF, in its world economic outlook (Gopinath 2020), documented that it was expected that the world economy would experience the worst COVID-19-related recession since the 1930s Great Depression $^{1}$. This unprecedented outcome not only upon human lives but also on the global economy was due to many governments implementing drastic measures to prevent the spread of COVID-19. They instituted lockdowns, strict quarantine policies, social distancing (Rahman et al. 2021) and travel bans both inward and outward.

On the other hand, to combat the above adversaries, governments also put huge economic stimulus packages through their monetary and fiscal policies. Since this study relates to Australian stock returns and their volatility, it would be pertinent to briefly describe how the monetary and fiscal tools used by the Australian federal government to support the economy. On the fiscal side, some of the major actions ${ }^{2}$ taken by the Australian government which are listed below in Table 1.

On the other hand, Australia adopted an expansionary monetary policy by reducing interest rates and simultaneously expansionary fiscal policy by increasing transfer payments. The Reserve Bank of Australia's (RBA) cash rate, which influences the market interest rate, was $0.75 \%$ in January 2020. However, to save the COVID-19 smashed economy, 
the RBA slashed its official cash rate three times in 2020 and, in February 2021, decided to let it stay at its current level of $0.10 \%{ }^{3}$.

Table 1. Australian government's economic stimulus in chronological order.

\begin{tabular}{|c|c|}
\hline Date & Australian Government's Fiscal Response \\
\hline 12 March 2020 & $\begin{array}{l}\text { This date marks the day the Australian federal government announced } \\
\text { its first economic package of } \$ 17.60 \text { billion. }\end{array}$ \\
\hline 3 March 2020 & $\begin{array}{l}\text { This date features the Australian government's announcement of its } \\
\text { second economic package of } \$ 130 \text { billion, including Jobseeker and } \\
\text { Jobkeeper payments to eligible applicants. }\end{array}$ \\
\hline 4 June 2020 & The Australian government announces its Home Builder Grant scheme. \\
\hline 21 July 2020 & This date marks the extension of the Jobkeeper payment. \\
\hline
\end{tabular}

Our study relates to the strand of literature that examines the effect of COVID-19 on stock market performance in terms of returns and returns' volatility. Given the time frame of our study, limited studies have examined the effect of the COVID-19 pandemic on stock market performance. Zhang et al. (2020), using a minimum spanning tree analysis, on top ten countries provide general patterns of risks associated with specific countries having the highest number of COVID-19 cases as of 27 March 2020. Their results suggest that stock market risks significantly rose in the sample countries. Also, the rise in the uncertainty of COVID-19 and its negative effect on the real economy has increased financial markets' volatility. Al-Awadhi et al. (2020) implement panel data analysis to examine the effect of COVID-19 on Chinese stock markets for the period 10 January 2020 to 16 March 2020. Their results suggest that COVID-19 has a significant negative effect on Chinese stock returns. Mazur et al. (2021) examine the performance of the US stock market (evidence from S\&P 500) and provide evidence that the stocks of natural gas, food, healthcare and software stocks earn higher positive returns, while on the other hand, stock prices of petroleum, real estate, entertainment and hospitality sectors fall dramatically because of COVID-19. This paper investigates the effect of COVID-19 on the volatility of Australian stock returns and further analyses the effect of both negative and positive news (shocks) on the volatility of Australian stock returns by investigating the presence of asymmetry and purportedly leverage.

In addition to the above, choosing the Australian stock market is motivated by several factors. Firstly, although Australia was not among the most affected nations in terms of human cost (death, physical effect of COVID-19 infection and mental trauma) ${ }^{4}$, its stock market was one of the most affected in the world, making it an interesting candidate for analysis. The benchmark Australian stock price index-S\&P/ASX $200^{5}$-declined more than $27 \%$, which was the most compared to top world stock price indices (see Table 2). Although the stock market seemed to be decoupled from the GFC, which originated in the USA in 2008, the reaction of the Australian stock market to the COVID-19 pandemic again makes it a strong point for our study. Our study aims to fill this gap by examining the effect of COVID-19 on the volatility of Australian stock returns using the top 200 Australian stocks by market capitalisation listed on S\&P/ASX200. We also analyse the impact of both negative and positive news (shocks) on the stock returns' volatility and investigate the asymmetric nature of the shocks' impact and the possible presence of leverage as a special case of asymmetry. 
Table 2. This table compares the percentage change in index values of top world indices over the period 31 January 2020 to 31 March 2020. The S\&P/ASX200 Index, shaded in grey, declines the most in comparison to top world indices.

\begin{tabular}{cccc}
\hline \multirow{2}{*}{ Index } & \multicolumn{2}{c}{ Index Value } & \multirow{2}{*}{ \% Age Change } \\
\cline { 2 - 3 } & 31 January 2020 & 31 March 2020 & \\
\hline EURO Stoxx 50 & 3639.00 & 2747.00 & $-24.51 \%$ \\
FTSE 100 & 7286.01 & 5671.96 & $-22.15 \%$ \\
NASDAQ Composite & 9150.94 & 7700.10 & $-15.85 \%$ \\
Nikkei 225 & $23,205.18$ & $18,917.01$ & $-18.48 \%$ \\
S\&P 500 & 3225.52 & 2584.59 & $-19.87 \%$ \\
S\&P ASX200 & 7017.20 & 5076.80 & $-27.65 \%$ \\
\hline
\end{tabular}

We employ the GARCHX model, which makes it possible to include variables of interest in both the mean and conditional variance specification. We use three proxies for COVID-19, namely: total number of confirmed cases due to COVID-19; the total number of deaths due to COVID-19; and a dummy variable indicating negative news for the period between 24 February 2020 to 22 March 2020. To capture the asymmetric effects of the random shocks, we utilise exponential GARCH (EGARCH), which capture asymmetry and leverage as a special case of asymmetry with appropriate restrictions imposed on the model's parameters. Asymmetry arises when the positive and negative shocks of the same magnitude have an unequal impact on returns volatility. On the other hand, according to McAleer and Hafner (2014), leverage as a special case of asymmetry is related to increased volatility. This is due to negative shocks to returns and a decline in volatility due to positive shocks to returns, so what it means that leverage captures the negative correlation between returns shocks and subsequent shocks to volatility.

The findings provide evidence that infectious diseases like COVID-19 can seriously impact stock market returns and their volatility. The findings could be of substantial interest to specific stakeholders, such as market participants, portfolio and hedge managers, regulators, and policymakers. The rest of the paper is organised as follows. In the subsequent sections, data and descriptive statistics are presented. In Section 3, we briefly elaborated on the choice of our model, while Section 4 presents an empirical study related to asymmetry, leverage and NIC for four models and monitor the impact of shocks on the conditional volatility of returns and forecasts evaluation in Section 5. Section 6 contains some concluding remarks.

\section{Data \& Descriptive Statistics}

We examine the effect of COVID-19 on the value-weighted returns (VWR) of Australian stock prices and their volatility. As our sample, we consider daily Australian stocks (close) prices data of 200 stocks listed on S\&P/ASX200 (ASX-200) taken from Yahoo Finance and covers the period 27 January 2020 to 29 December $2020^{6}$. We choose 27 January 2020 as the start of our period because the very first case of COVID-19 infection was reported on 26 January 2020 for Australia. Due to the non-availability of stocks data for Caltex Australia and TPG Telecom Ltd for the period of our interest and missing values of United Malt Group from 27 January 2020 to 22 March 2020, we use stock prices of 197 stocks of ASX-200 in our study. Following Apergis and Apergis (2020), we employ the total number of confirmed cases of COVID-19 (COVID-19A) and the number of deaths due to COVID-19 (COVID-19B) as proxies for COVID-19's effect on the VWR of the stocks of ASX-200 and their volatility ${ }^{7}$. The data for COVID-19A and COVID-19B are obtained from Our World in Data. 
Additionally, to capture the effect of negative news, following Rahman et al. (2021), we also introduce a dummy variable in our model representing negative news (COVID19C) as a proxy for the COVID-19 effect on the VWR of the stocks of ASX-200 and their volatility. However, the use of the dummy variable differs from Rahman et al. (2021) in that instead of being only a specific date, we use this dummy variable for 24 February 2020 to 22 March 2020. The date 24 February 2020 is the day on which the Australian Health Protection Principal Committee (AHPPC) issued a statement on COVID-19 ${ }^{8}$, stating that if COVID-19 develops as a pandemic, then its widespread community transmission would almost be impossible to prevent. Hence a significant local outbreak would place enormous pressure on the healthcare system. Then on 11 March 2020, WHO did declare that COVID-19 a pandemic by saying that "we are deeply concerned both by the alarming levels of spread and severity and by the alarming levels of inaction. We have therefore made the assessment that COVID-19 can be characterised as a pandemic" ${ }^{\prime \prime}$. Such a situation could be a blow to the economy without adequate financial support from the government. Thus, the impact of the negative news was likely to persist until the Government intervenes to save the economy substantially. We consider 22nd March 2020 as the date that features the Australian federal government's economic response to COVID-19 by announcing its second economic stimulus package of $\$ 130$ billion.

Thus, our selected period from 24 February 2020 to 22 March 2020 signifies the time of negative news due to COVID-19's effect on the VWR of ASX-200 stocks and their volatility (see panel A of Figure 1). To better visualise the returns volatility, we compute the variance of returns using a rolling window having a length of 22 days and present the information in Panel B of Figure 1. We find there is a significant rise in the variance from 5.7 to 22.37 on the dates when the first news (AHPPC's statement) and the first economic package of AUD 17.6 billion was announced. However, we observe the volatility continues to rise and reaches the maximum of 25.43 on 19 March 2020 and only drops to 24.99, indicating the first economic response was not very effective in terms of reducing stock market volatility. However, what is notable is a significant and rapid decline in volatility after the second economic package of AUD 130 billion was announced, incorporating the Jobseeker and Jobkeeper payments to eligible individuals and businesses. We observe that from the beginning of May 2020, the volatility has been consistently below 2.63. Thus, the visualisation provides insights that both positive and negative news affect volatility; a negative news increases volatility and vice-versa, albeit with asymmetric effects.

For this reason, we intend to explore the impact of news together with the effects caused by changes in both interest rate and the relative oil price on the VWR-ASX200 volatility. Hence, following Apergis and Apergis (2020), this paper employs daily data of a 1-month interbank interest rateto proxy for short-term interest rates and crude oil prices. The data on interest rates and crude oil prices are obtained from the Reserve Bank of Australia and Yahoo Finance, respectively. We do not have missing values in our final dataset. Summary statistics and correlation matrix on these variables are presented in Table 3. 
Panel A

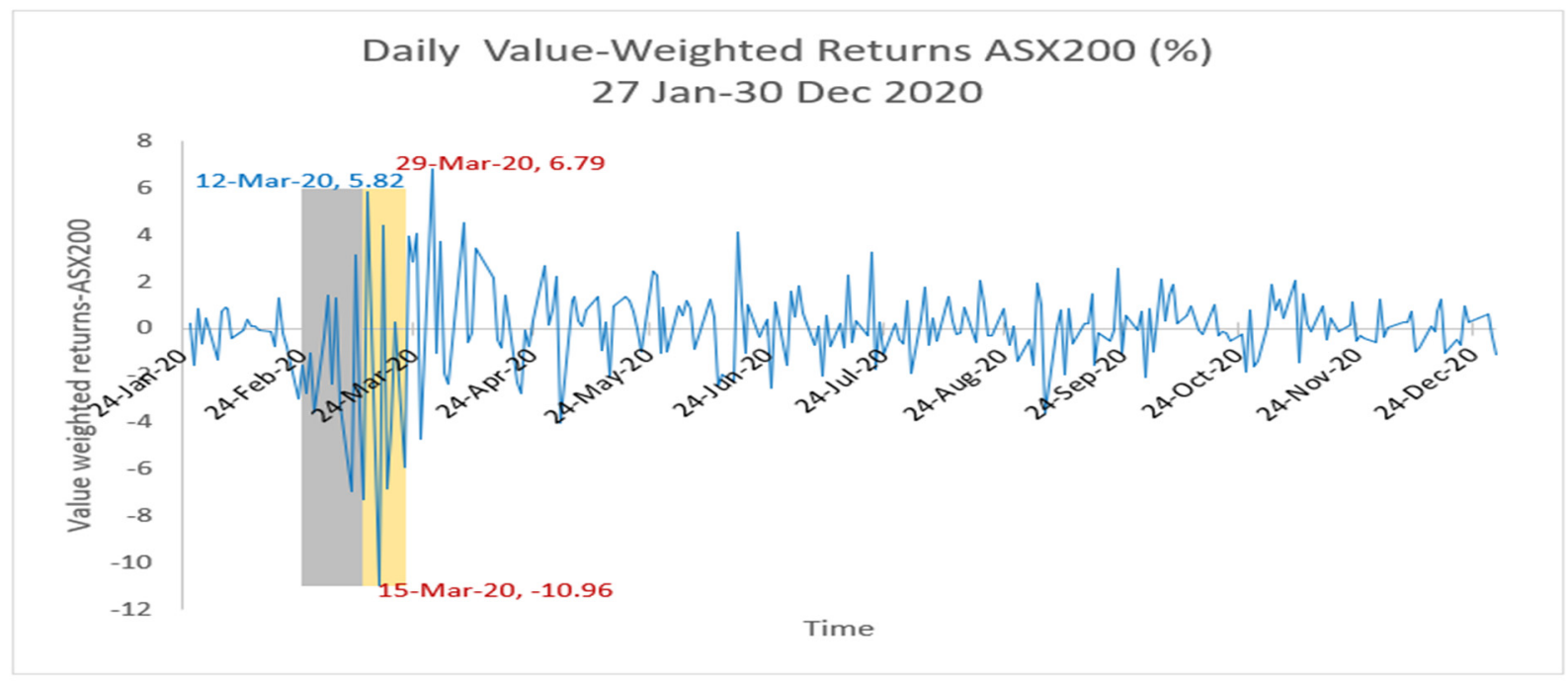

Panel B

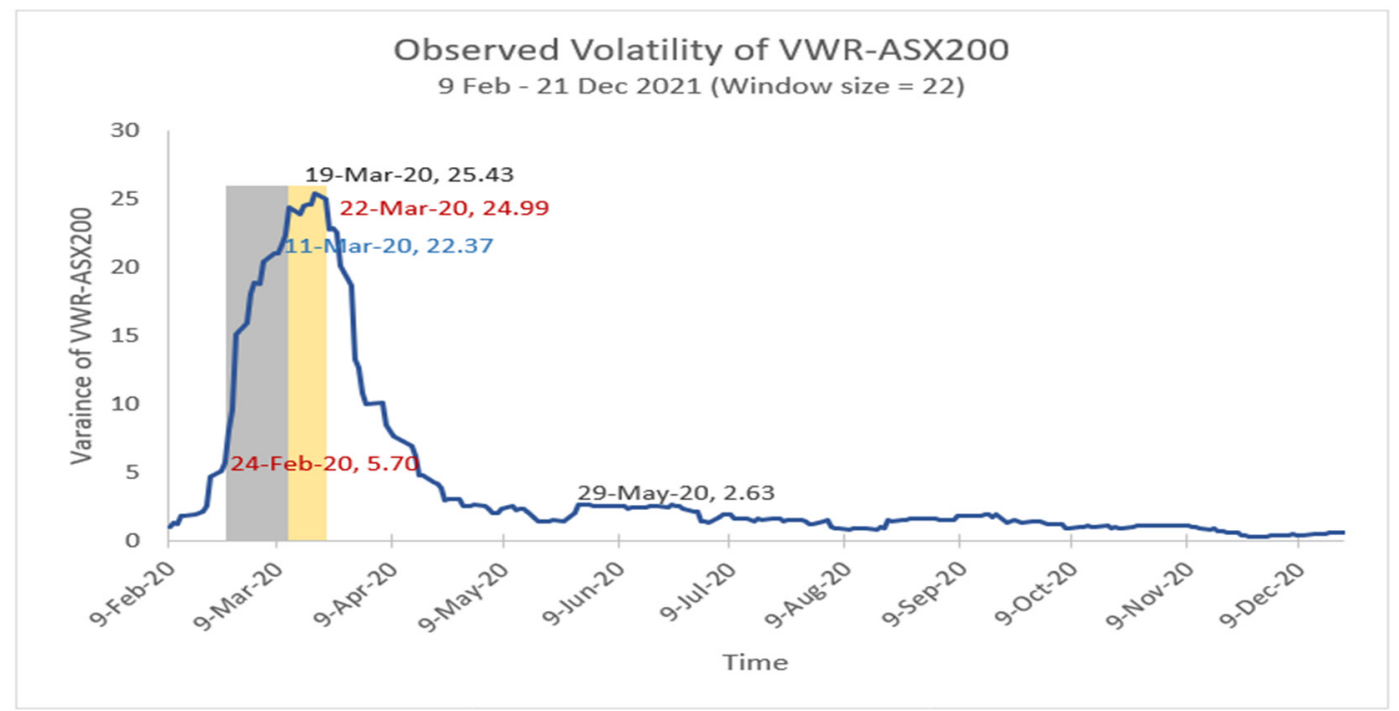

Figure 1. Panel A shows the daily realised VWR of S\&P/ASX200 from 27 January 2020 to 30 December 2020. It illustrates specifically the rise in the volatility of daily realised VWR between 12 March 2020 and 29 March 2020. Panel B depicts the observed volatility of VWR of S\&P/ASX200 from 27 January 2020 to 31 December 2020 with a specific spike from 12 March 2020 to 29 March 2020. VWR-ASX200 is the value-weighted return of 197 stocks listed in S\&P/ASX200 at levels. In panels A and B, we use data of 197 stocks listed on S\&P/ASX200 from 27 January 2020 to 30 December 2020 to examine the effect of COVID-19 on Australian stock returns and their volatility. VWR-ASX200 is the value-weighted return of 197 stocks listed in S\&P / ASX200 at level, Oil Price is the international crude oil price to the order I(1), Interest rate is Australian one-month interbank interest rate to the order I(1), COVID-19A represents the total number of confirmed cases in Australia due to COVID-19 to the order I(1), COVID-19B represents the total number of deaths in Australia due to COVID-19 to the order I(1) and COVID-19C is a dummy variable depicting the negative news, and it takes a value of 1 from 24 February 2020 to 22 March 2020 otherwise 0. 
Table 3. Panel A shows the summary statistics for the variables used in the specifications. We use data of 197 stocks listed on S\&P / ASX200 from 27 January 2020 to 30 December 2020 to examine the effect of COVID-19 on Australian stock returns and their volatility. VWR-ASX200 is the value-weighted return of 197 stocks listed in S\&P/ASX200 at level, Oil Price is the international crude oil price to the order I(1), Interest rate is Australian one-month interbank interest rate to the order I(1), COVID-19A represents the total number of confirmed COVID-19 cases in Australia to the order I(1), COVID-19B represents the total number of deaths in Australia due to COVID-19 to the order I(1). Meanwhile, COVID-19C is a dummy variable depicting the negative news, and it takes a value of 1 from 24 February 2020 to 22 March 2020, otherwise 0.

\begin{tabular}{|c|c|c|c|c|c|c|c|c|c|}
\hline \multicolumn{10}{|l|}{ Panel A } \\
\hline Variables & $\begin{array}{c}\text { Order of } \\
\text { Integration }\end{array}$ & $\mathbf{N}$ & Mean & $\begin{array}{l}\text { Std. } \\
\text { Dev. }\end{array}$ & Median & Min & Max & Kurtosis & Skewness \\
\hline VWR-ASX200 & $\mathrm{I}(0)$ & 238 & -0.029 & 1.959 & 0.107 & -10.956 & 6.791 & 8.905 & -1.056 \\
\hline Oil Price & $\mathrm{I}(1)$ & 238 & -0.030 & 1.696 & 0.000 & -13.400 & 5.010 & 20.372 & -2.342 \\
\hline Interest Rate & $\mathrm{I}(1)$ & 238 & -0.004 & 0.018 & 0.000 & -0.142 & 0.073 & 18.367 & -1.964 \\
\hline COVID-19A & $\mathrm{I}(1)$ & 238 & 119.332 & 224.916 & 23.500 & 0.000 & 1450.000 & 14.964 & 3.209 \\
\hline COVID-19B & $\mathrm{I}(1)$ & 238 & 3.819 & 8.972 & 0.000 & 0.000 & 59.000 & 23.178 & 4.175 \\
\hline Panel B & & & & & & & & & \\
\hline Variables & & & \multicolumn{2}{|c|}{ VWR-ASX200 } & Oil Price & $\begin{array}{c}\text { Interest } \\
\text { Rate }\end{array}$ & $\begin{array}{l}\text { COVID- } \\
19 A\end{array}$ & \multicolumn{2}{|c|}{ COVID-19B } \\
\hline VWR-ASX200 & 1 & & \multicolumn{2}{|c|}{1.0000} & & & & & \\
\hline Oil Price & 2 & & \multicolumn{2}{|c|}{0.2448 * } & 1.0000 & & & & \\
\hline Interest Rate & 3 & & \multicolumn{2}{|c|}{$-0.3001 *$} & -0.1599 & 1.0000 & & & \\
\hline COVID-19A & 4 & & \multicolumn{2}{|c|}{0.0807} & -0.0338 & -0.0926 & 1.0000 & \multirow{2}{*}{\multicolumn{2}{|c|}{1.0000}} \\
\hline COVID-19B & 5 & & & & 0.0166 & 0.0244 & $0.5016^{*}$ & & \\
\hline
\end{tabular}

Note that ${ }^{*}$ represents significance at the $10 \%$ level.

\section{Methodology and Empirical Design}

To model volatility and its forecasting in time series, the GARCH (generalised autoregressive conditional heteroskedasticity) model proposed by Bollerslev (1986) is very popular in the scientific community. Since Bollerslev (1986), several variants of GARCH models have been presented, which include integrated GARCH-IGARCH (Engle and Bollerslev 1986), exponential GARCH-EGARCH (Nelson 1991) and GARCHX that was promoted by Engle et al. (1990), Apergis (1998) and Connor et al. (2006).

This paper considers GARCHX and EGARCH models to examine the effect of COVID19 on value-weighted returns of Australian stock prices. The motivation to select these models comes from prior studies discussing the correlation between stock returns and their volatility (Al-Awadhi et al. 2020; Zhang et al. 2020; Mazur et al. 2021). The EGARCH model is particularly useful for measuring the asymmetric effects of news and the consequent leverage if it exists. Both these volatility models are introduced with additional covariates that can affect the mean of stock returns in the GARCH equation. Since we are specifically interested in examining the impact of the COVID-19 shock on the average and conditional volatility of stock returns, we include this factor in both the conditional mean and variance equations. GARCH models are preferable over the ARCH models because (1) we do not require non-negativity constraint in parameters (2) GARCH $(1,1)$ and $\operatorname{EGARCH}(1,1)$ models are capable of capturing higher order $\mathrm{ARCH}(\mathrm{p}, \mathrm{q})$ models.

Moreover, it is well established in the literature that oil prices (Cologni and Manera 2008; Kilian 2009; Nguyen and Bhatti 2012; Reboredo and Rivera-Castro 2014) and interest rates (Laopodis 2013; Huang et al. 2016; Assefa et al. 2017) are useful in determining the stock prices and stock returns. For this reason, we also include both percentage changes in oil prices and the changes in the short-term interest rates as covariates in the mean equation of both the volatility models. The mean equation of our volatility models takes a common form as shown below in Equation (1); nonetheless, the conditional variances of the two models are presented in Equations (2) and (3) below. 
Mean Equation:

$$
R_{t}=\mu_{0}+\sum_{i=1}^{p} \phi_{i} R_{t-i}+\sum_{j=1}^{q} \psi_{j} \varepsilon_{t-j}+\varphi_{1} \operatorname{COVID} 19_{t}+\varphi_{2} \Delta \ln \left(\text { Oil }_{t}\right)+\varphi_{3} \Delta \text { Int Rate } t+\varepsilon_{t},
$$

where $R_{t}$ represents the value-weighted return of 197 stocks listed on S\&P ASX-200. The first sum is the autoregressive (AR) component, with $\mu_{0}$ and $\varepsilon_{t-j}$ being a constant and the error term, respectively. Since we are using the GARCHX variant of the GARCH family, so we have added COVID19 $t$ which is composed of COVID19-A, COVID19-B and COVID19-C (see Section 2). Moreover, literature has established a role of oil prices (Cologni and Manera 2008; Kilian 2009; Nguyen and Bhatti 2012; Reboredo and Rivera-Castro 2014) and interests rates (Laopodis 2013; Huang et al. 2016, Assefa et al. 2017) in determining the stock prices and stock returns, so Equation (1) also includes both oil prices as $\mathrm{Oil}_{t}$ and short-term interest as IntRatet.

Conditional Volatility or Variance Equation:

$$
\begin{gathered}
\operatorname{GARCHX}(1,1): h_{t}=\omega_{1}+\alpha_{1} \varepsilon^{2}{ }_{t-1}+\beta_{1} h_{t-1}+\delta_{1} \operatorname{COVID} 19_{t}, \\
\operatorname{EGARCH}(1,1): \ln \left(h_{t}\right)=\omega+\beta \ln \left(h_{t-1}\right)+\alpha\left|\eta_{t-1}\right|+\gamma \eta_{t-1}+\delta \operatorname{COVID} 19_{t},
\end{gathered}
$$

where $h_{t}$ represents conditional volatility and the variable, $\eta_{t}=\varepsilon_{t} / \sqrt{h_{t}}$ denotes the standardised errors.

Throughout, we assume that the random shocks, $\varepsilon_{t}$ follow Generalized Error Distribution (GED) such that $\varepsilon_{t} \sim G E D\left(0, H_{t}, v\right)$, where $v$ is the shape parameter that would also be estimated along with the other parameters. ${ }^{10}$ To estimate these models, we will apply the Quasi-Maximum Likelihood Estimation (QMLE) method using EVIEWS 11. Note that by setting $\delta_{1}=0$ in Equation (2), the GARCHX model reduces to a simple GARCH model. Following Bollerslev (1986), we require the constraints, $\omega_{1}>0, \alpha_{1} \geq 0, \beta_{1} \geq 0$ and $\alpha_{1}+\beta_{1}<1$ such that the conditional variances or the GARCH term, $h_{t}$, are postive and stationary. Furthermore, the restriction $\alpha_{1}+\beta_{1}<1$ is a sufficient condition to ensure that the QMLE of GARCH(1,1) model in Equation (2) are consistent and asymptotically normal (Chang and McAleer 2017). Likewise, as stated in He et al. (2002) and McAleer and Hafner (2014), the EGARCH model will be stable only if $|\beta|<1$, whereas the asymmetry holds if $\gamma \neq 0$. Meanwhile, leverage exists when we observe $\gamma<0$ and $\gamma<\alpha<-\gamma$. This justifies the choice of our model(s) to conduct empirical analysis which is done in the next section.

\section{Empirical Analysis}

Our empirical analysis in this section begins with the identification of an optimal ARIMA (ARIMAX) model and then followed by estimating ARCH/GARCH specification. In the diagnostic part, firstly, we execute a graphical plot of all the time series used in our study. A visual analysis indicates that the variables do not show a trend and that the fluctuations in each series are around its mean but with a larger variability (refer to Figure 2). Secondly, we apply the Box-Jenkins methodology and obtain ARMA $(1,11)$ with covariates as a parsimonious model for our mean equation. To identify the possible presence of heteroskedasticity and the $\mathrm{ARCH}$ effects, we construct correlograms of the squared residuals in Figure 3 below. This qualitative analysis reveals significant $\mathrm{ARCH}$ effects in both the initial model (with constant only) and ARMA $(1,11)$ model. The outcome is also confirmed by the Breusch-Pagan test of heteroskedasticity and the LM test, respectively (see panel B of Table 2. The results in panel B of Table 4 confirms the presence of heteroskedasticity and (G)ARCH effect, also evident from the correlogram of residuals squared from the mean equation with constant only and ARMA $(1,11)$ models (see Figure 3 ).

We estimate the parameters of the GARCHX model using Equations (2) and (3); for brevity, results are not presented here. The findings concerning three alternative model specifications correspond to three alternative proxies of COVID-19 variables. Column 1 corresponds to COVID-19A, i.e., the total number of confirmed cases of COVID-19, column 
2 relates to COVID-19B, i.e., the total number of deaths due to COVID-19 and column 3 parallels to COVID-19C. It is a dummy variable that depicts the negative news, and it takes a value of 1 from 24 February 2020 to 22 March 2020 otherwise 0 . In the mean equation, while the coefficients of COVID-19A and COVID-19B are positive and insignificant, the coefficient of COVID-19C provides evidence that COVID-19 has a negative and statistically significant effect on Australian stock returns. Surprisingly, the coefficients of COVID19A and COVID-19B are insignificant. However, a negative and statistically significant coefficient of COVID-19C implies that the stock market has already taken the effect of negative news and may explain why the coefficients of COVID-19A and COVID-19B are insignificant. Most importantly, the model provides evidence across all specifications, i.e., from column 1 to column 3 , to predict negative stock returns for tomorrow as the coefficients of $V W R-A S X 200_{t-1}$ are negative and overwhelmingly statistically significant.

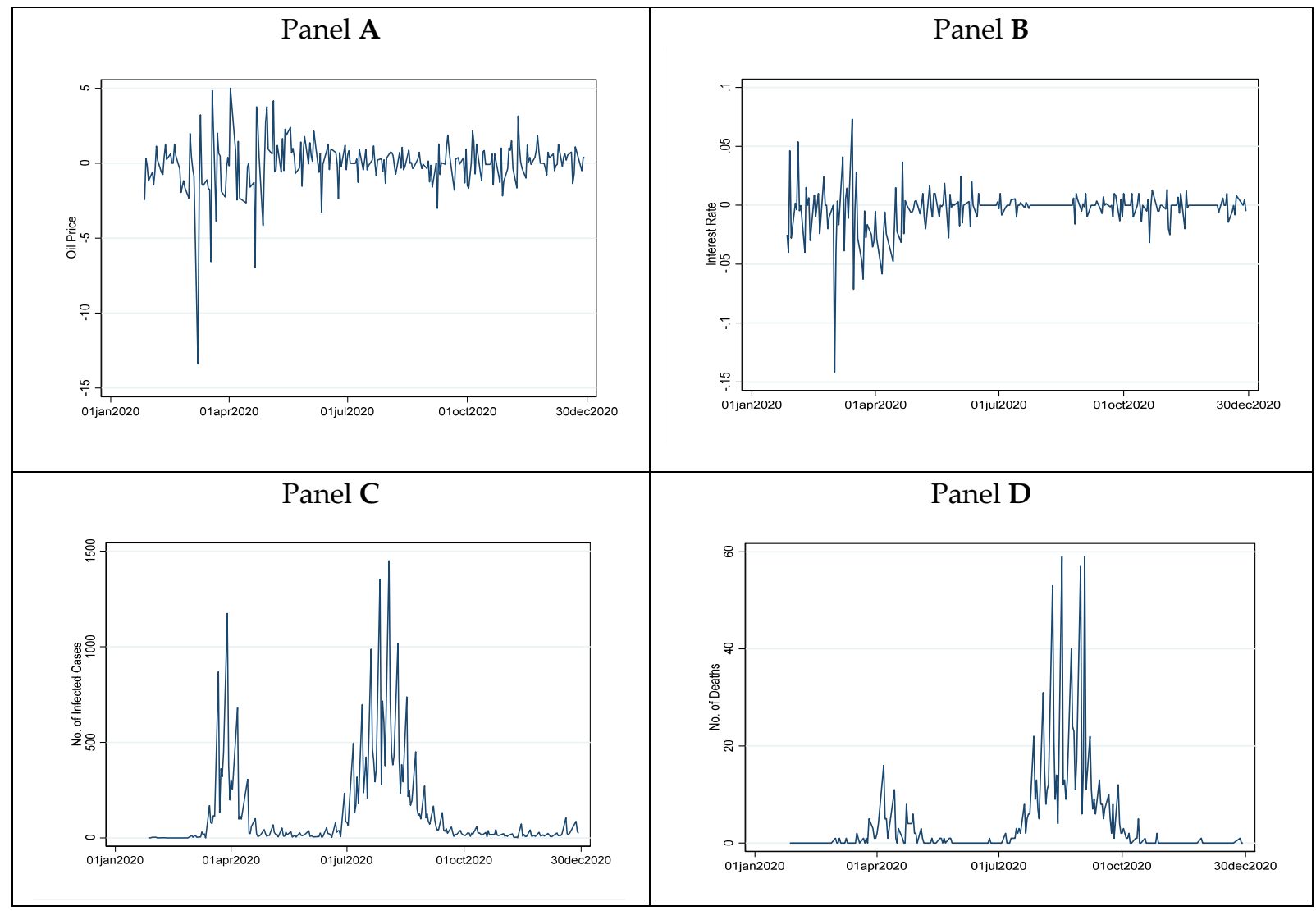

Figure 2. Panel (A) shows the first difference of Oil Price, Panel (B) depicts the first difference of Interest rates, Panel (C) presents the first difference of the number of confirmed cases from COVID-19, while Panel (D) is the first difference of the number of deaths due to COVID-19. We use data of 197 stocks listed on S\&P/ASX200 from 27 January 2020 to 30 December 2020 to examine the effect of COVID-19 on Australian stock returns and their volatility. VWR-ASX200 is the value-weighted return of 197 stocks listed in S\&P/ASX200 at level, Oil Price is the international crude oil price to the order I(1), the Interest rate is Australian one-month interbank interest rate to the order I(1), COVID-19A represents the total number of confirmed cases in Australia due to COVID-19 to the order I(1), COVID-19B represents the total number of deaths in Australia due to COVID-19 to the order I(1) and COVID-19C is a dummy variable depicting the negative news, and it takes a value of 1 from 24 February 2020 to 22 March 2020 otherwise 0. 


\begin{tabular}{|c|c|c|c|}
\hline \multicolumn{2}{|c|}{$\begin{array}{l}\text { Mean Equation: } R_{t}=\mu_{0}+\varepsilon_{t} \\
l=22 \text { lags }\end{array}$} & \multicolumn{2}{|c|}{ 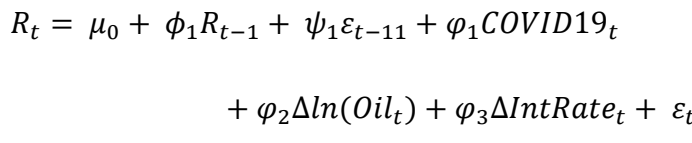 } \\
\hline Autocorrelation & Partial Correlation & Autocorrelation & Partial Correlation \\
\hline $1 \longmapsto$ & $1 \sqsubseteq$ & $1 \square$ & $1 \square$ \\
\hline$\square$ & $\square$ & 河 & 1 \\
\hline $1 \boxminus$ & $1]$ & 1曰 & 卢 \\
\hline $1 \emptyset$ & 1 1 & 1 & 1. 1 \\
\hline ' & $1 \square$ & '万 & 1 1 \\
\hline $1 曰$ & $\sqrt[15]{1}$ & 1曰 & 的 \\
\hline , $\boxminus$ & 다 & ון 1 & 101 \\
\hline 味 & 12 & 1 / & $1] 1$ \\
\hline 邑 & 12 & $\square$ & 10 \\
\hline$\square$ & 1] & 1 ? & 1디 1 \\
\hline 号 & 至! & $1 \sqrt{19}$ & 1 \\
\hline 泊 & 111 & in & 1, \\
\hline 19 & $1 / 1$ & 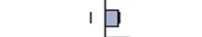 & $1 \overline{7}$ \\
\hline $1 曰$ & 101 & 1曰 & 101 \\
\hline 111 & 1 & 1 & 10 \\
\hline 101 & $1] 1$ & $1 \sqrt{1}$ & id 1 \\
\hline $1 / 1$ & $1 \mid 1$ & 1 p & $1 / 1$ \\
\hline 111 & 101 & $1 \sqrt{1}$ & 1 \\
\hline 11 & 1 & $1] 1$ & 1] 1 \\
\hline 1. 1 & 1 & 1 & 1 1 \\
\hline 1|1 & ין & 1미 1 & 미 \\
\hline
\end{tabular}

Figure 3. The diagram shows the correlograms of squared residuals. We use data of 197 stocks listed on S\&P/ASX200 from 27 January 2020 to 30 December 2020 to examine the effect of COVID-19 on Australian stock returns and their volatility. VWR-ASX200 is the value-weighted return of 197 stocks listed in S\&P/ASX200 at level, Oil Price is the international crude oil price to the order I(1), the Interest rate is Australian one-month interbank interest rate to the order I(1), COVID-19A represents the total number of confirmed cases in Australia due to COVID-19 to the order I(1), COVID-19B represents the total number of deaths in Australia due to COVID-19 to the order I(1) and COVID-19C is a dummy variable depicting the negative news, and it takes a value of 1 from 24 February 2020 to 22 March 2020 otherwise 0.

Table 4. Panel A shows the values of $R^{2}$ taken from regression output and Durbin-Watson statistic (DW) fetched after running the regression. A comparison of these shows that DW statistic $>R^{2}$. Panel B presents the Breusch test for heteroskedasticity and the LM Test to observe the ARCH Effect. In the heteroskedasticity test, the null hypothesis for homoskedasticity is rejected in favour of heteroskedasticity. In the ARCH effect, the null hypothesis for no ARCH effect is rejected in favour of the presence of ARCH effects. We use data of 197 stocks listed on S\&P/ASX200 from 27-01-2020 to 30-12-2020 to examine the effect of COVID-19 on Australian stock returns and their volatility. VWR-ASX200 is the value-weighted return of 197 stocks listed in S\&P/ASX200 at level, Oil Price is the international crude oil price to the order I(1), the Interest rate is Australian one-month interbank interest rate to the order I(1), COVID-19A represents the total number of confirmed cases in Australia due to COVID-19 to the order I(1), COVID-19B represents the total number of deaths in Australia due to COVID-19 to the order I(1) and COVID-19C is a dummy variable depicting the negative news, and it takes a value of 1 from 24-02-2020 to 22-03-2020 otherwise 0 .

\begin{tabular}{ccc}
\hline Panel-A & & \\
\hline $\mathrm{R}^{2}$ & 0.2491 & \\
Durbin-Watson Statistic & 2.84 & \\
\hline Panel-B & & 0.0000 \\
\hline LM Test of ARCH effects & 75.6858 & \\
\hline
\end{tabular}

Similarly, in the conditional volatility equation, the results show that the dummy for COVID-19, when included in the variance equation, has a positive and statistically significant effect on tomorrow's volatility of stock returns. The impact of COVID-19 is more pronounced for COVID-19C, i.e., the negative news relating to COVID-19. Additionally, 
among the drivers of stock returns, crude oil prices have the expected, i.e., positive and significant effect on stock returns for all the specifications. In contrast, while the interest rate is insignificant for the specifications in columns 1 and 2, it has the expected sign (negative) with a statistically significant effect on stock returns for the specification in column 3 .

\subsection{Analysis of GARCH and EGARCH Models}

Table 5 provides the estimation results of the GARCH and EGARCH models with and without news. From the results under the mean equation, we observe that the constant term is not statistically significantly different from zero in all the models. This outcome is not unexpected based on the mean value or the observed returns from the descriptive statistics. We also observe negative but statistically significant autocorrelation of the current period returns with its own one-period (day) lag values, $V W R-A S X 200_{t-1}$. Similarly, the individual coefficients of both the percentage change in oil price and the moving average term, $\mathrm{MA}(11)$, are positive and statistically significant. In contrast, the interest rate changes wield a negative impact which is insignificant in the GARCH(1,1)-without News specification, but significant in GARCH(1,1)-with News, EGARCH(1,1)-with News and EGARCH(1,1)-without News models. However, the coefficient is weakly significant in the EGARCH-with News specification. A potential explanation of this weak significance is the strong stance of the RBA to keep the target cash rate low with changes from $0.75 \%$ to $0.5 \%$ to $0.25 \%$ on the 4 th and 20th March, respectively, and $0.1 \%$ on 4 th November 2020 . We observe that the first two changes correspond to the period where the returns were extremely volatile as can be seen in Figure 2. Overall, we observe the consistency in the signs of the covariates with only minor variation in the sizes across the models in the mean equation.

When analysing the GARCH $(1,1)$ without news specification, we observe that the coefficient estimates satisfy the constraints $\hat{\omega}_{1}=0.0942>0, \hat{\alpha}_{1}=0.2002>0, \hat{\beta}_{1}=$ $0.7688>0$, and $\hat{\alpha}_{1}+\hat{\beta}_{1}=0.97<1$ (where this condition implies that the QMLE of the GARCH model is consistent with approximately normal distribution). However, we note that the constant term, $\omega_{1}$ is statistically insignificant. In the case of the GARCH $(1,1)$ with the News model, we observe that the coefficient, $\delta_{1}$ of COVID- $19 C_{t}$ is positive and statistically significant, implying that positive news impacts the returns positively and vice-versa. In contrast to the model with no news, the results reveal that $\alpha_{1} \geq 0$ constraint is statistically highly significant, while $\hat{\beta}_{1}>1$ implies a long memory of the volatility (which is explosive in nature). Also, the GARCH model assumes symmetric effects of both positive and negative shocks on volatility. For these reasons, we pay attention to the asymmetric or EGARCH model.

We observe all the coefficients in the conditional variance equation of the EGARCH models without and with news are statistically significant, including the intercept term (that has weak significance). We also observe that the stability condition $\beta<1$ is also satisfied. Furthermore, the negative estimates of the coefficient $\alpha$ of $\left|\frac{\text { Resid }_{t-1}}{\sqrt{\text { GARCH }_{t-1}}}\right|$ implies the asymmetric effect of negative news than the positive news of the same magnitude. Meanwhile, the coefficient $\gamma$ of $\frac{\text { Resid }_{t-1}}{\sqrt{G A R C H_{t-1}}}$ has a negative estimated value and is highly significant, thus indicating the existence of the leverage effect. That is, positive shocks cause volatility to decrease and vice-versa. Also, in the EGARCH model with news, the statistically significant coefficient of the news dummy variable with positive value indicates that positive news will diminish volatility and vice-versa. The results not shown here; however, $\operatorname{GARCH}(1,1)$, EGARCH(1,1) models are still preferable to higher order variants based on the AIC. 
Table 5. This table shows GARCHX estimates to show the effect of COVID-19 on the VWR of ASX200 and their volatility. We use data of 197 stocks listed on S\&P/ASX200 from 27 January 2020 to 30 December 2020 to examine the effect of COVID-19 on Australian stock returns and their volatility. VWR-ASX200 is the value-weighted return of 197 stocks listed in S\&P/ASX200 at level, Oil Price is the international crude oil price to the order I(1), the Interest rate is Australian one-month interbank interest rate to the order I(1), COVID-19A represents the total number of confirmed cases in Australia due to COVID-19 to the order I(1), COVID-19B represents the total number of deaths in Australia due to COVID-19 to the order I(1) and COVID-19C is a dummy variable depicting the negative news, and it takes a value of 1 from 24 February 2020 to 22 March 2020 otherwise 0.

\begin{tabular}{|c|c|c|c|c|}
\hline & $\begin{array}{l}\text { GARCH(1,1) } \\
\text { without News }\end{array}$ & $\begin{array}{l}\text { GARCH(1,1) } \\
\text { with News }\end{array}$ & $\begin{array}{l}\text { EGARCH } \\
\text { without News }\end{array}$ & $\begin{array}{l}\text { EGARCH } \\
\text { with News }\end{array}$ \\
\hline \multicolumn{5}{|l|}{ Mean Equation } \\
\hline \multirow[t]{2}{*}{ COVID-19C $C_{t}$} & & $-2.5263^{* * *}$ & $-1.277^{* * *}$ & $-2.428^{* * *}$ \\
\hline & & [0.559] & {$[0.452]$} & {$[0.607]$} \\
\hline \multirow[t]{2}{*}{$V W R-A S X 200_{t-1}$} & $-0.2080^{* * *}$ & $-0.2734^{* * *}$ & $-0.260 * * *$ & $-0.279^{* * *}$ \\
\hline & {$[0.072]$} & {$[0.056]$} & {$[0.053]$} & [0.055] \\
\hline \multirow[t]{2}{*}{$\Delta \ln \left(\right.$ Oil Price $\left._{t}\right)$} & $3.9184^{* * *}$ & $4.881^{* * *}$ & $4.152 * * *$ & $4.1313^{* *}$ \\
\hline & [1.6164] & [1.695] & {$[1.533]$} & {$[1.678]$} \\
\hline \multirow[t]{2}{*}{$\Delta\left(\right.$ Interest Rate $\left._{t}\right)$} & -5.5980 & $-9.4148^{* *}$ & $-12.534^{* * *}$ & $-9.3966^{*}$ \\
\hline & [4.995] & [4.779] & [4.477] & [5.186] \\
\hline \multirow[t]{2}{*}{$M A(11)$} & $0.1404^{* *}$ & $0.1276^{* *}$ & $0.1780^{* * *}$ & $0.1550 * *$ \\
\hline & [0.063] & [0.064] & [0.057] & [0.061] \\
\hline \multirow[t]{2}{*}{ Constant } & 0.0921 & 0.0842 & -0.0401 & 0.033 \\
\hline & [0.087] & [0.090] & {$[0.074]$} & [0.087] \\
\hline \multirow[t]{2}{*}{ COVID-19C $t$} & & $0.5925^{* * *}$ & & $0.1260^{* * *}$ \\
\hline & & [0.159] & & [0.0402] \\
\hline \multirow[t]{2}{*}{$A R C H_{t-1}$} & $0.2002^{* *}$ & $-0.0417^{* * *}$ & & \\
\hline & [0.079] & [0.011] & & \\
\hline \multirow[t]{2}{*}{$(\ln ) G A R C H_{t-1}$} & $0.7688^{* * *}$ & $1.0165^{* * *}$ & $0.9905^{* * *}$ & $0.9865^{* * *}$ \\
\hline & {$[0.084]$} & [0.0002] & [0.000] & {$[0.000]$} \\
\hline \multirow[t]{2}{*}{$\left|\frac{\text { Resid }_{t-1}}{\sqrt{\text { GARCH }_{t-1}}}\right|$} & & & $-0.0823 * *$ & $-0.0950^{* *}$ \\
\hline & & & {$[0.0412]$} & {$[0.0478]$} \\
\hline \multirow[t]{2}{*}{$\frac{\text { Resid }_{t-1}}{\sqrt{\text { GARCH }_{t-1}}}$} & & & $-0.231^{* * *}$ & $-0.1424^{* *}$ \\
\hline & & & [0.054] & [0.067] \\
\hline \multirow[t]{2}{*}{ Constant } & 0.0942 & 0.0186 & $0.0710 *$ & 0.0723 * \\
\hline & {$[0.074]$} & {$[0.014]$} & {$[0.036]$} & {$[0.037]$} \\
\hline Log Likelihood & -412.3250 & -395.2095 & -395.4455 & -390.9372 \\
\hline R-Squared & 0.1736 & 0.3471 & 0.3153 & 0.3356 \\
\hline Adjusted R-Squared & 0.1593 & 0.3329 & 0.3005 & 0.3012 \\
\hline Durbin-Watson Stat & 2.0760 & 2.3343 & 2.195 & 2.2960 \\
\hline
\end{tabular}

Note that * represents significance at the $10 \%$ level, ${ }^{* *}$ at the $5 \%$ level and ${ }^{* * *}$ at the $1 \%$ level.

\subsection{News Impact Curve}

To further support the presence of asymmetry and leverage, we plot the news impact curves (NIC) using the parameters' estimates from all four models and monitor the impact of shocks on the conditional volatility of returns. Details on various specifications of 
the NIC corresponding to variants of the GARCH model can be found in Caporin and Costola (2019). Asymmetry of the GARCH model requires that the past positive and negative shocks of the same magnitude have different effects on the conditional volatility, that is, NIC $\left(\left|\epsilon_{t-1}\right|\right) \neq N I C\left(-\left|\epsilon_{t-1}\right|\right)$. As stated earlier, the leverage effect holds when a positive shock reduces volatility, but a negative shock leads to an increase in the conditional volatility.

From Figure 4 below, we find that the GARCHX $(1,1)$-Without News is a symmetric and U-shaped curve implying that the past positive and negative shocks of the same magnitude have the same effect on the conditional volatility. Also, we find the larger the magnitude of the shock, the larger the impact there is on the volatility. However, GARCHX $(1,1)$ model-With News is unstable since $\hat{\beta}_{1}>1$ and provides negative volatilities for larger shocks which is not possible. For this reason, we do not interpret this unstable model.

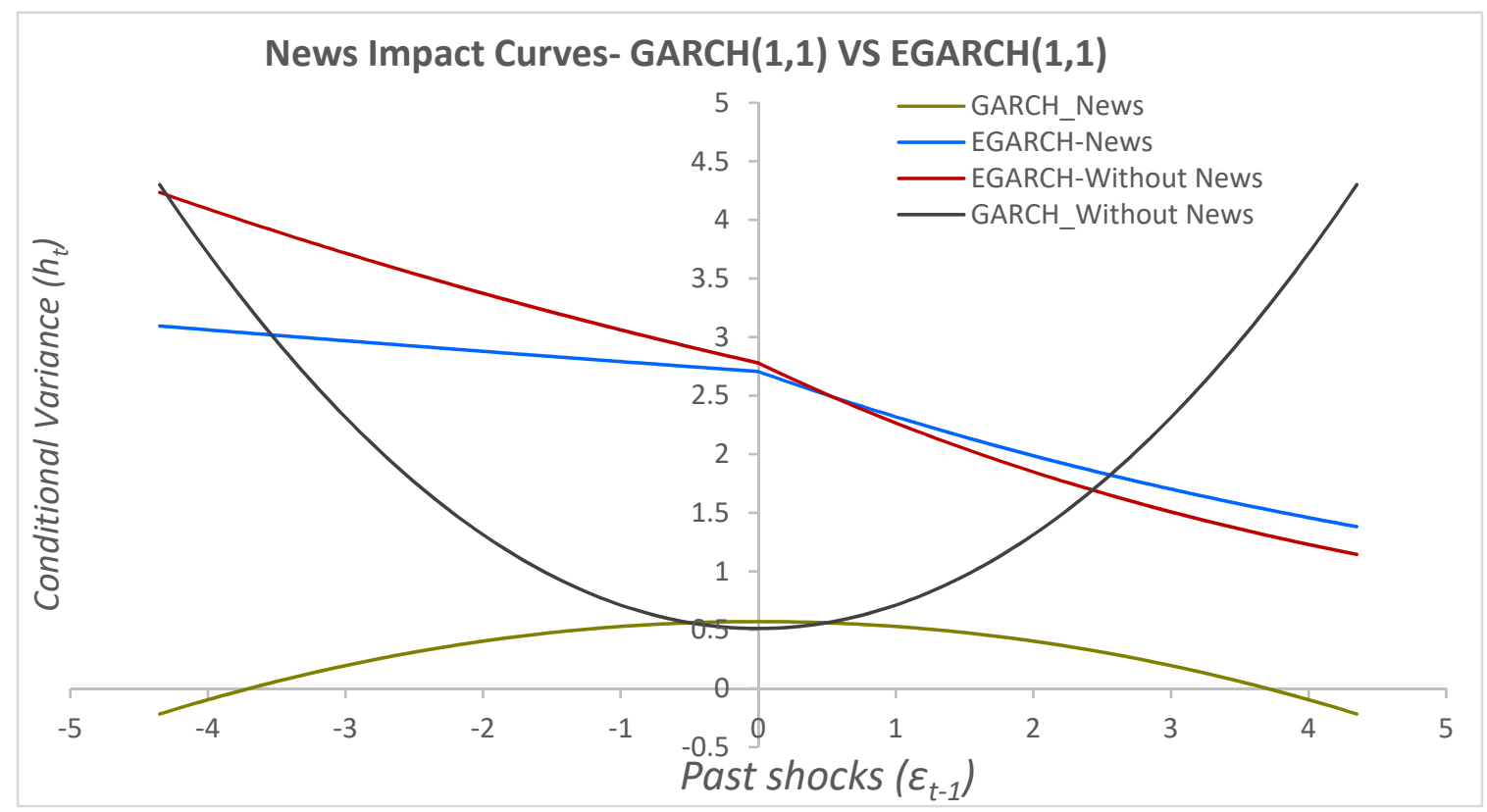

Figure 4. This figure shows the news impact curve in the GARCHX model with \& without news and the EGARCH model. We use data of 197 stocks listed on S\&P/ASX200 from 27 January 2020 to 30 December 2020 to examine the effect of COVID-19 on Australian stock returns and their volatility. VWR-ASX200 is the value-weighted return of 197 stocks listed in S\&P / ASX200 at level; Oil Price is the international crude oil price to the order I(1), the Interest rate is Australian one-month interbank interest rate to the order I(1), COVID-19A represents the total number of confirmed cases in Australia due to COVID-19 to the order I(1), COVID-19B represents the total number of deaths in Australia due to COVID-19 to the order I(1), and COVID-19C is a dummy variable depicting the negative news, and it takes a value of 1 from 24 February 2020 to 22 March 2020 otherwise 0.

In the case of the asymmetric model-EGARCH with and without news, we observe asymmetry and the leverage effect of shocks in the volatility of ASX-200 returns. However, another interesting finding is that the EGARCH model with volatility equation without news demonstrates a larger (smaller) leverage effect of the negative (positive) shocks on the conditional volatility compared to its variant with the news. This outcome is obvious from the larger magnitude of $\hat{\gamma}$ from the model without news compared to the estimation from the model with news in the volatility equation. So, the EGARCH model conforms to asymmetry and leverage, whether the dummy for news is included in the conditional volatility equation. When the announcement of negative news by AHPPC that the COVID-19 developing into a pandemic and that a local outbreak would place enormous pressure on the healthcare system (see Section 2), stocks of companies in S\&P ASX 200 decreased substantially, causing the leverage to increase. The higher level of leverage led the perception of the risk associated with the companies in S\&P ASX 200 to 
increase with the volatility of their stocks. Therefore, we observe higher volatility on the release of negative news versus when the positive news arrives on the market. On the other hand, this unequal impact on volatility corresponds to the asymmetry effect.

\section{Forecast Evaluation}

Finally, we evaluate the EGARCH models with and without news using the outof-sample forecast for the next seven days. The results are reported in Table 6 below, where we do not observe any significant difference between the Root Mean Square Errors (RMSE), Mean Absolute Error (MAE) and Theil U2 coefficients. For each model, the value of the Theil U2 coefficient indicates the underlying model is superior to the naïve model. However, the Mean Absolute Percentage Error (MAPE) is slightly lower for the model with the news. We also perform the Diebold-Mariano (DM) forecast evaluation test and observe that the test fails to reject the null of equal forecast accuracy (using absolute or squared loss functions). Hence both models are equally preferable in terms of their forecast evaluation.

Table 6. Out-of-Sample (7 days) Forecast Evaluation. Value in the square bracket denotes the $p$-value of the DM test using the MAE loss function. The same results hold if we use the MSE as the error criterion.

\begin{tabular}{ccc}
\hline & \multicolumn{2}{c}{ EGARCH } \\
\hline Measures & Without News & With News \\
\hline RMSE & 0.7411 & 0.7427 \\
MAE & 0.6362 & 0.6328 \\
MAPE & 94.6095 & 87.5828 \\
Theil U2 & 0.7749 & 0.7606 \\
DM Test & 0.3107 & \\
& {$[0.7560]$} & \\
\hline
\end{tabular}

\section{Concluding Remarks}

This paper examines the impact of COVID-19 on the volatility of Australian stock returns. It further examines the presence of asymmetry and suspected leverage due to both negative and positive news (shocks) on the volatility of Australian stock returns by employing GARCHX (1,1), EGARCH(1,1) and News impact curve (NIC). We observe some of the following important findings.

(i) COVID-19 has a negative effect on Australian stock returns in both GARCHX $(1,1)$ and $\mathrm{EGARCH}(1,1)$ specifications.

(ii) We also find that the negative news has increased the volatility of Australian stock returns for both GARCHX $(1,1)$ and $\operatorname{EGARCH}(1,1)$ with News (negative news) specifications.

(iii) We further find that the GARCHX (1,1)-with News model and GARCHX (1,1)-without News model exhibit symmetry. However, EGARCH(1,1) with the News model and EGARCH $(1,1)$ without News model indicates the presence of asymmetry and leverage.

To further validate the presence of symmetry in GARCHX $(1,1)$ without News and GARCHX $(1,1)$ with News models and the presence of asymmetry and purported leverage in EGARCH(1,1)-without News and EGARCH(1,1)-with News models, we employ NIC. It is also observed that NIC shows that GARCHX $(1,1)$-without News is symmetric, implying that the past positive and negative shocks of the same magnitude have the same effect on the conditional volatility. On the other hand, NIC shows that GARCHX $(1,1)$ with News is unstable. In terms of both the models of $\operatorname{EGARCH}(1,1)$, the NIC confirms the presence of asymmetry and leverage. NIC provides another interesting finding that the EGARCH model with volatility equation without news demonstrates a larger (smaller) leverage effect of the negative (positive) shocks on the conditional volatility compared to its variant with the news. The findings suggest that $\operatorname{EGARCH}(1,1)$ can represent the 
asymmetric conditional volatility process for daily returns time series of ASX-200. The forecast evaluation of both the specifications of $\operatorname{EGARCH}(1,1)$ suggest that both the models are preferable; however, EGARCH is superior to a naïve model.

Author Contributions: Conceptualization and validation, all three authors; methodology, software \& formal analysis N.I. and M.S.M.; original draft preparation, N.I.; writing-review and editing, N.I., M.S.M. \& M.I.B.; supervision and project administration, M.I.B. All authors have read and agreed to the published version of the manuscript.

Funding: This research received no external funding.

Institutional Review Board Statement: Not applicable.

Informed Consent Statement: Not applicable.

Data Availability Statement: Not applicable.

Acknowledgments: We are thankful to the four anonymous reviewers, handling special issue editor Robert Brooks and the Editor of the JRFM for their constructive comments which have improved the quality of the papers. However, the authors take sole responsibility for all remaining errors.

Conflicts of Interest: The authors declare no conflict of interest.

\section{Notes}

$1 \quad$ The IMF in its report stated: “This is a crisis like no other, and there is substantial uncertainty about its impact on people's lives and livelihoods. A lot depends on the epidemiology of the virus, the effectiveness of containment measures, and the development of therapeutics and vaccines, all of which are hard to predict. In addition, many countries now face multiple crises-a health crisis, a financial crisis, and a collapse in commodity prices, which interact in complex ways. Policymakers are providing unprecedented support to households, firms, and financial markets, and, while this is crucial for a strong recovery, there is considerable uncertainty about what the economic landscape will look like when we emerge from this lockdown" (World Economic Outlook, April 2020).

2 The Australian government provided financial support to individuals and businesses in the form of Jobkeeper payment, Jobseeker and other income support payments, reduced drawdown and deeming rates for retirees, home builder grant, COVID-19 support on state level basis, financial support for business and emergency, crisis, and legal support. (https://moneysmart.gov.au/covid-19 / financial-assistance, accessed on 20 February 2021). https:/ / rba.gov.au/statistics/cash-rate/ (accessed on 20 February 2021).

4 https://www.who.int/docs / default-source/coronaviruse / situation-reports /20200505covid-19-sitrep-106.pdf?sfvrsn=47090f63_2 (accessed on 27 January 2020).

5 The routine was developed in Python 3 to download the entire sample set.

6 Since this data is either steady and incremental the difference could either be 0 or positive, but it can never be negative. For this reason data is adjusted from 2 June 2020 to 22 June 2020 by increasing 1 number i.e., from 102 to 103 to bring it equal to the level of 1 June 2020. The number of deaths on 23 June 2020 is also 103. www.health.gov.au/news/australian-health-protection-principal-committee-ahppc-statement-on-coronavirus-covid-19-24-february2020 (accessed on 13 February 2021).

8 https://www.who.int/director-general/speeches/detail/who-director-general-s-opening-remarks-at-the-media-briefing-on-covid19---11-march-2020 (accessed on 7 July 2021).

$9 \quad v<(>) 2$ implies that GED has thicker (thinner) tails compared to the normal distribution, but GED is identical to the normal distribution when $v=2$. Given the high kurtosis values of the returns, it is plausible to assume a thick-tailed distribution of the errors.

10 https://www.rba.gov.au/statistics/cash-rate/ (accessed on 7 July 2021).

\section{References}

Al-Awadhi, Abdullah M., Khaled Alsaifi, Ahmad Al-Awadhi, and Salah Alhammadi. 2020. Death and contagious infectious diseases: Impact of the COVID-19 virus on stock market returns. Journal of Behavioral and Experimental Finance 27: 100326. [CrossRef] [PubMed]

Apergis, Nicholas. 1998. Stock market volatility and deviations from macroeconomic fundamentals: Evidence from GARCH and GARCH-X models. Kredit und Kapital 31: 400-12.

Apergis, Nicholas, and Emmanuel Apergis. 2020. The role of Covid-19 for Chinese stock returns: Evidence from a GARCHX model. Asia-Pacific Journal of Accounting E Economics 2020: 1-9. 
Assefa, Tibebe A., Omar A. Esqueda, and André Varella Mollick. 2017. Stock returns and interest rates around the World: A panel data approach. Journal of Economics and Business 89: 20-35. [CrossRef]

Bakas, Dimitrios, and Athanasios Triantafyllou. 2020. Commodity price volatility and the economic uncertainty of pandemics. Economics Letters 193: 109283. [CrossRef]

Baumeister, Christiane, and James D. Hamilton. 2019. Structural interpretation of vector autoregressions with incomplete identification: Revisiting the role of oil supply and demand shocks. American Economic Review 109: 1873-910. [CrossRef]

Bollerslev, Tim. 1986. Generalised autoregressive conditional heteroskedasticity. Journal of Econometrics 31: 307-27. [CrossRef]

Caporin, Massimiliano, and Michele Costola. 2019. Asymmetry and leverage in GARCH models: A News Impact Curve perspective. Applied Economics 51: 3345-64. [CrossRef]

Chang, Chia-Lin, and Michael McAleer. 2017. The correct regularity condition and interpretation of asymmetry in EGARCH. Economics Letters 161: 52-55. [CrossRef]

Cologni, Alessandro, and Matteo Manera. 2008. Oil prices, inflation and interest rates in a structural cointegrated VAR model for the G-7 countries. Energy Economics 30: 856-88. [CrossRef]

Connor, Gregory, Robert A. Korajczyk, and Oliver Linton. 2006. The common and specific components of dynamic volatility. Journal of Econometrics 132: 231-55. [CrossRef]

Engle, Robert F., and Tim Bollerslev. 1986. Modelling the persistence of conditional variances. Econometric Reviews 5: 1-50. [CrossRef]

Engle, Robert F., Victor K. Ng, and Michael Rothschild. 1990. Asset pricing with a factor-ARCH covariance structure: Empirical estimates for treasury bills. Journal of Econometrics 45: 213-37. [CrossRef]

Gopinath, Gita. 2020. The great lockdown: Worst economic downturn since the great depression. IMF Blog 14: 2020.

He, Changli, Timo Teräsvirta, and Hans Malmsten. 2002. Moment structure of a family of first-order exponential GARCH models. Econometric Theory 18: 868-85. [CrossRef]

Huang, Wanling, André Varella Mollick, and Khoa Huu Nguyen. 2016. US stock markets and the role of real interest rates. The Quarterly Review of Economics and Finance 59: 231-42. [CrossRef]

Kilian, Lutz. 2009. Not all oil price shocks are alike: Disentangling demand and supply shocks in the crude oil market. American Economic Review 99: 1053-69. [CrossRef]

Laopodis, Nikiforos T. 2013. Monetary policy and stock market dynamics across monetary regimes. Journal of International Money and Finance 33: 381-406. [CrossRef]

Mazur, Mieszko, Man Dang, and Miguel Vega. 2021. COVID-19 and the march 2020 stock market crash. Evidence from S\&P1500. Finance Research Letters 38: 101690. [PubMed]

McAleer, Michael, and Christian M. Hafner. 2014. A one line derivation of EGARCH. Econometrics 2: 92-97. [CrossRef]

Nelson, Daniel B. 1991. Conditional heteroskedasticity in asset returns: A new approach. Econometrica: Journal of the Econometric Society 1991: 347-70. [CrossRef]

Nguyen, Cuong C., and M. Ishaq Bhatti. 2012. Copula model dependency between oil prices and stock markets: Evidence from China and Vietnam. Journal of International Financial Markets, Institutions and Money 22: 758-73. [CrossRef]

Rahman, Md Lutfur, Abu Amin, and Mohammed Abdullah Al Mamun. 2021. The COVID-19 outbreak and stock market reactions: Evidence from Australia. Finance Research Letters 38: 101832. [CrossRef]

Reboredo, Juan C., and Miguel A. Rivera-Castro. 2014. Wavelet-based evidence of the impact of oil prices on stock returns. International Review of Economics \& Finance 29: 145-76.

Zhang, Dayong, Min Hu, and Qiang Ji. 2020. Financial markets under the global pandemic of COVID-19. Finance Research Letters 36: 101528. [CrossRef] [PubMed] 